\title{
DESARROLLO DE SISTEMA DE VISIÓN ARTIFICIAL PARA CONTROL DE CALIDAD DE BOTELLAS EN LA EMPRESA CARTAVIO RUM COMPANY
}

\section{Development of artificial vision system for quality control of bottles in the company Cartavio Rum Company}

\author{
Ryan Abraham León León ${ }^{1}$, Bebeto Junior Beltran Jara ${ }^{1}$, Renato Cruz Saavedra ${ }^{1}$, Kendy Terrones Julcamoro ${ }^{1}$, \\ Alexander Torres Verastegui ${ }^{1}$, Miguel Angel Aponte de la Cruz ${ }^{1}$ \\ ${ }^{1}$ Universidad Privada del Norte, Facultad de Ingeniería Industrial, Perú. \\ Email:ryan.leon@upn.edu.pe,74486747bjbj@gmail.com,cruz_renato@gmail.com, \\ kendy.terronesjul@gmail.com, toveras_alex@gmail.com,miguelaponte1999@gmail.com
}

(Recibido Mayo 21 de 2018 y aceptado Abril de 2019)

\section{Resumen}

El presente artículo tiene por objetivo desarrollar un sistema de control de calidad de bebidas embotelladas para la empresa Cartavio Rum Company mediante el software Visual Studio 2017, empleando el algoritmo transformado de hough y canny para los bordes y aplicación de filtros morfológicos (erode). Este sistema consta de una banda transportadora que genera el movimiento de las botellas, hasta ser detectadas por la cámara, la cual obtiene las imágenes que son procesadas. Para ello se tiene un sistema para el ingreso de las botellas hacia la faja transportadora que serán llevadas hasta el lugar de captura de las imágenes realizada mediante un software que se encarga de identificar del nivel de llenado del producto, evaluar la alineación y el correcto color de las etiquetas de la botella, también verificar el control de sedimentos o pequeños cuer-pos extraños en el contenido de las botellas, para luego realizar el pre procesamiento de las mismas. Al finalizar el pre-procesamiento y determinar las características finales del producto mediante parámetros preestablecidos en bebidas embotelladas de ron, mediante el uso de visión artificial, las botellas que pasen el control continúan hacia un proceso de ubicación en las cajas donde serán despachadas y aquellas que no cumplen son rechazadas y reprocesadas. Se realizaron diversas pruebas que concluyen que el sistema de visión artificial muestra una eficiencia del 95\% comparado al de la inspección visual del ojo humano con 55\%, corroborando la efectividad de la visión artificial en el proceso de calidad en la empresa.

Palabras clave: calidad, inspección, visión artificial.

\begin{abstract}
This article aims to develop a quality control system for bottled beverages for Cartavio Rum Company by using Visual Studio 2017 software, using the transformed hough and canny algorithm for borders and the application of morphological filters (erode). This system consists of a conveyor belt that generates the movement of the bottles, until it is detected by the camera, which obtains the images that are processed. For this, there is a system for the entry of the bottles to the conveyor belt, which will be taken place of capture of the images made by software. It identifies the level of loading of the product, evaluate the alignment and the correct color of the labels of the bottle, also it verify the control of sediments or small strange bodies in the bottles contents, then perform the previous processing the same. At the end of the preprocessing and determine the final characteristics of the product through pre-established parameters in bottled rum drinks, by using artificial vision, the bottles that pass the control continue towards a place process in the boxes where they can be dispatched and controlled, those that do not comply are rejected and reprocessed. Several tests concluded that the artificial vision system showed an efficiency of $95 \%$ compared to visual inspection
\end{abstract}


of the human eye with 55\%, corroborating the effectiveness of artificial vision in the quality process in the company.

Key words: quality, inspection, artificial vision.

\section{INTRODUCCIÓN}

En la actualidad, se ha logrado combinar exitosamente varias disciplinas, con el propósito de crear métodos de fabricación más eficientes. Los sistemas de inspección automatizados nacen al fusionar múltiples especialidades como la informática, visión artificial y automatización. Las oportunidades para la implementación de estos sistemas se encuentran en tareas de inspección, selección de productos, control de calidad, embalaje y monitorización de procesos. La visión artificial se basa en la adquisición de imágenes, en dos dimensiones, para procesarlas digitalmente mediante algún tipo de computador con el fin de extraer y medir determinadas propiedades de las imágenes adquiridas. Por lo tanto se trata, de una tecnología que combina las computadoras con las cámaras de video para adquirir y analizar imágenes de una forma equivalente a la inspección visual humana [1].

A medida que pasa el tiempo la tecnología es más indispensable en la industria ya que los procesos son reali-zados a gran velocidad y pueden presentar fallas que no son visibles o detectado por el ojo humano y requie-ren de métodos más avanzados, con el fin de evitar productos de baja calidad, cansancio, estrés y pérdida de visión en los trabajadores.

Son múltiples las ventajas que se pueden obtener al reemplazar los métodos tradicionales por sistemas de control de calidad automatizados. Estos sistemas brindan la posibilidad de inspeccionar toda la producción a grandes velocidades; además permiten complementar sentidos humanos como la vista y el tacto en aquellos lugares en donde la monotonía, velocidad, peligrosidad o el coste, entre otros, hacen inviable el uso de operarios. Gracias a todas sus características, ésta tecnología ha conseguido una gran aceptación por las industrias de todo el mundo, y se está empleando cada vez con mayor frecuencia [2].
En este orden de ideas, esta investigación se plantea implementar un sistema de visión artificial para el control de procesos en la línea de proceso de embotellado de ron de la empresa Cartavio Rum Company, debido a que permite incrementar los niveles de producción en empresas que trabajan a grandes velocidades por la gran demanda que requiere el mercado, dicho proceso brinda solución en la detección de las fallas, anoma-lías y productos mal terminados en un determinado proceso.

\section{METODOLOGÍA}

Se realizó el siguiente procedimiento: - Adquisición o captura de la imagen: La primera etapa es la construcción del sistema de formación de las imágenes. Su objetivo es realzar, mediante técnicas fotográficas (iluminación, óptica, cámaras, filtros, pantallas, etc.), las características visuales de los objetos (formas, texturas, colores, sombras, etc.). El éxito de muchas aplicaciones depende de un buen diseño en esta primera etapa.

- Pre procesamiento: Este grupo de funciones se especializa en realizar mejoras a la imagen captada, es decir resalta un sin número de características que conllevan a elevar la calidad de la imagen a la hora de ser analizada. En esta etapa se incluyen operaciones como: mejora de la relación señal- ruido, atenuar las imperfecciones de la adquisición debido a la función de transferencia del sistema de captación de imágenes, regularizar la imagen, mejorar el contraste $u$ optimizar la distribución de la intensidad y realzar algunas características de la imagen, como bordes o áreas.

- Segmentación: La clasificación de la escena en sus partes u objetos es a lo que se le llama segmentación de la imagen. Por ejemplo, en una imagen de satélite se determina las zonas de agua, de cultivo, urbanas, carreteras, etc. Existen varias técnicas: Umbralizaciones, discontinuidades, crecimiento de regiones, uso del 
color o de movimiento, etc. Estas técnicas se basan en encontrar dónde se encuentran grupos de pixeles que conformen un ente a clasificar (objeto), para ello estas técnicas se basan en los principios de discontinuidad y similitud.

- Representación y descripción: Estas técnicas se basan en extraer, del ente a estudiar, las características que lo diferencian de los demás. Para realizar esta extracción de características es necesario realizar un estudio del objeto a analizar y extraer con cuidado las características invariantes que posea. Éstas deben ser, gene-ralmente, independientes a rotaciones, escalamientos corrimientos de dicho objeto. Básicamente, son de tipo morfológico, tales como: área, perímetro, excentricidad, momentos de inercia, esqueletos; no obstante, también se puede emplear características basadas en la textura o en el color.

- Reconocimiento e interpretación: Una vez obtenidas las características que describen el objeto a estudiar, se pasa al reconocimiento del mismo, esto no es más que la clasificación, utilizando cualquier técnica conocida, llámese inteligencia artificial, búsquedas deductivas en base de datos, comparación con patrones etc. Dentro de las técnicas más utilizadas se encuentra la utilización de redes neuronales artificiales, algoritmos genéticos y métodos estadísticos avanzados.

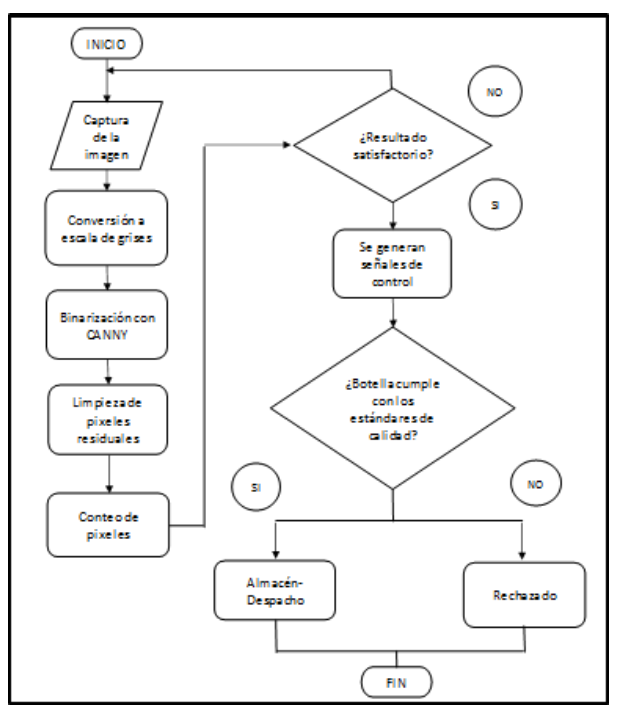

Figura 1. Flujograma de algoritmo de proceso.

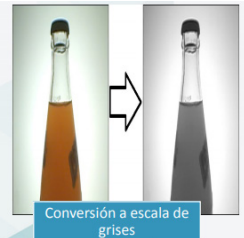

Figura
2.

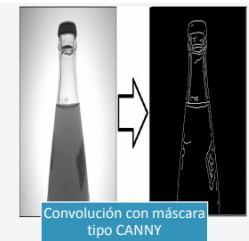

Adquisición

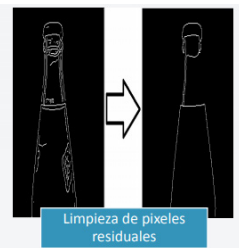

imágenes.
Observación: El conteo de pixeles se realiza en el centro de la imagen, contando los pixeles negros desde la parte inferior de la botella hasta la parte superior esto hasta encontrar el pixel blanco el cual representa el nivel de llenado [3-5].

Visión Artificial:

Tabla 1. Ejemplo de tabla para la publicación de artículos

\begin{tabular}{|c|c|}
\hline Código para adquirir video & $\begin{array}{c}\text { Aspectos } \\
\text { Seleccionados }\end{array}$ \\
\hline $\begin{array}{l}\text { handles.vidobj = videoinput('win- } \\
\text { video',1); start(handles.vidobj); } \\
\text { guidata(hObject, handles); src_obj } \\
\text { =getselectedsource(handles. } \\
\text { vidobj); get(src_obj); vidRes = ge- } \\
\text { t(handles.vidobj, 'VideoResolution'); } \\
\text { preview(handles.vidobj,hlmage); } \\
\text { axis off catch }\end{array}$ & $\begin{array}{l}\text { Evento que se } \\
\text { ejecuta al } \\
\text { oprimir el botón } \\
\text { cámara }\end{array}$ \\
\hline Código para capturar imagen & Descripción \\
\hline $\begin{array}{l}\text { [nom-bre,ruta]=uigetfile('*.avi','SE- } \\
\text { LECCIONE EL VIDEO EN FORMATO } \\
\text { AVI'); if nombre == } 0 \text { set(hOb- } \\
\text { ject,'Enable','on'); set(handles. } \\
\text { inicio,'Enable','on'); set(handles. } \\
\text { parar,'Enable','on'); return }\end{array}$ & $\begin{array}{l}\text { Evento que se } \\
\text { ejecuta al } \\
\text { oprimir el botón } \\
\text { video }\end{array}$ \\
\hline \multicolumn{2}{|l|}{ Fuente: autores } \\
\hline \multicolumn{2}{|c|}{$\begin{array}{l}\text { Pre procesamiento de imagen: } \\
\text { Tabla 2. Ejemplo de tabla para la publicación de artículos }\end{array}$} \\
\hline Código para escala de grises & Descripción \\
\hline $\begin{array}{c}\text { grisesb=rgb2gray(imagengray); } \\
\text { background3=grisesb; axes(hand- } \\
\text { les.background3); axis off; } \\
\text { imshow(background3); handles. } \\
\text { imagen_M=grisesb; guidata(hOb- } \\
\text { ject, handles); }\end{array}$ & $\begin{array}{l}\text { Evento que se } \\
\text { ejecuta automá- } \\
\text { ticamente para } \\
\text { el pre proce- } \\
\text { samiento de la } \\
\text { imagen }\end{array}$ \\
\hline
\end{tabular}

Fuente: autores 
Procesamiento de la imagen:

Tabla 3. Ejemplo de tabla para la publicación de artículos

\section{Código para los filtros}

Descripción

var=fix(handles.slider_ruido); se = strel('disk', var); filtroRGB = imsubtract(imadd(imagenruido,imtopha$\mathrm{t}$ (imagenruido,se)), imbothat(imagenruido,se)); else var=fix(handles. slider_ruido); se = strel('disk',var); filtroRGB = imsubtract(imadd(imagenruido,imtophat(imagenruido,s imsubtract(imadd(imagenruido,imtophat(imagenruido,se)), imbothat(imagenruido,se)); End

\section{Código para binarizacion}

Descripción

binaria1=im2 bw (imagenbina, 0.5$)$;

background3=binaria1; axes(hand-

les.background3); axis off; imshow(-

background3); handles.ima-

Evento en el que

Evento en el que se ejecutan diversos filtros

para evitar

el ruido en la imagen

gen_M=binaria1; guidata(hObject, handles);

\begin{tabular}{cc}
\hline Código para extracción de bordes & Descripción \\
\hline $13=e$ edge(segmento,'canny'); & $\begin{array}{c}\text { Evento en el que } \\
13=(\sim \mid 3) ; \text { for } i=1: 800, \text { waitbar(i/800) } \\
\text { end }\end{array}$ \\
$\begin{array}{c}\text { se extraen los } \\
\text { rasgos a }\end{array}$ \\
\hline
\end{tabular}

Fuente: autores

La función que desempeña cada una de estas etapas fue primordial ya que gracias a estas se realizaron ajustes en el sistema para la clasificación de las señales de entrada en una de las clases predefinidas. En base al análisis de ciertas características con el empleo de algoritmos para la detección de bordes de las personas se pudo clasificar satisfactoriamente señales de entrada $[6,7]$. Para la extracción de bordes en los individuos se tomó en cuenta los factores como fuentes de ruido, deformaciones, giros bruscos en la captura de imágenes y deformaciones en ellas mediante lo cual se pudo establecer los elementos del sistema inteligente.

\section{RESULTADOS}

Al término de la implementación del sistema desarrollado, objeto de esta tesis se han obtenido los siguientes resultados de acuerdo con los objetivos planteados en un inicio. La valoración del software está afirmada en su arquitectura. A continuación, la Tabla 4 Prueba grupo de módulos. Tabla 4. Prueba grupo de módulos

\section{PRUEBAS DEL SISTEMA INTELIGENTE DE} RECONOCIMIENTO DE PATRONES

\begin{tabular}{|c|c|c|c|c|}
\hline \multicolumn{2}{|c|}{ Nombre Prueba } & \multicolumn{3}{|c|}{ Grupo de módulos } \\
\hline \multicolumn{2}{|c|}{ Realizada por } & \multicolumn{3}{|c|}{ Programador } \\
\hline \multicolumn{2}{|r|}{ Descripción } & \multicolumn{3}{|c|}{$\begin{array}{l}\text { Evaluar y depurar cada interfaz de } \\
\text { usuario del sistema }\end{array}$} \\
\hline $\mathbf{N}^{\circ}$ & Categoría & $\begin{array}{l}\text { Respuesta } \\
\text { esperada de } \\
\text { la interfaz } \\
\text { de usuario }\end{array}$ & $\begin{array}{l}\text { Incre- } \\
\text { mental } \\
\text { ascen- } \\
\text { dente }\end{array}$ & $\begin{array}{l}\text { Incre- } \\
\text { mental } \\
\text { descen- } \\
\text { dente }\end{array}$ \\
\hline 1 & $\begin{array}{l}\text { Visión } \\
\text { Artificial }\end{array}$ & $\begin{array}{l}\text { Captura y } \\
\text { visualización } \\
\text { de imagen }\end{array}$ & OK & OK \\
\hline 2 & $\begin{array}{l}\text { Visión } \\
\text { Artificial }\end{array}$ & $\begin{array}{l}\text { Extracción } \\
\text { de bordes y } \\
\text { contornos }\end{array}$ & OK & --- \\
\hline 3 & $\begin{array}{l}\text { Visión } \\
\text { Artificial }\end{array}$ & $\begin{array}{l}\text { Segmenta- } \\
\text { ción }\end{array}$ & OK & --- \\
\hline 4 & $\begin{array}{l}\text { Visión } \\
\text { Artificial }\end{array}$ & $\begin{array}{l}\text { Detección } \\
\text { y reconoci- } \\
\text { miento de } \\
\text { patrones }\end{array}$ & OK & --- \\
\hline 5 & $\begin{array}{l}\text { Comunica- } \\
\text { ción ina- } \\
\text { lámbrica }\end{array}$ & $\begin{array}{l}\text { Sistema de } \\
\text { alerta auto- } \\
\text { mática }\end{array}$ & OK & --- \\
\hline
\end{tabular}

Fuente: autores

Tabla 5. Prueba sistema completo

\section{PRUEBAS DEL SISTEMA INTELIGENTE DE RECONOCIMIENTO DE PATRONES}

\begin{tabular}{cl} 
Nombre Prueba & Sistema completo \\
\hline Realizada por & Programador \\
\hline Descripción & $\begin{array}{l}\text { Evaluar y depurar el sistema } \\
\text { SISREP completo }\end{array}$ \\
\hline
\end{tabular}


Ryan Abraham León León Bebeto Junior Beltran Jara Renato Cruz Saavedra Kendy Terrones Julcamoro Miguel Angel Aponte de la Cruz Alexander Torres Verastegui

\begin{tabular}{|c|c|c|c|c|c|}
\hline $\mathbf{N}^{\circ}$ & $\begin{array}{l}\text { Catego- } \\
\text { ría }\end{array}$ & $\begin{array}{c}\text { Respuesta } \\
\text { esperada } \\
\text { del sistema } \\
\text { PIVRA }\end{array}$ & $\begin{array}{l}\text { Velo- } \\
\text { cidad }\end{array}$ & $\begin{array}{l}\text { Exacti- } \\
\text { tud }\end{array}$ & $\begin{array}{l}\text { Fiabi- } \\
\text { lidad }\end{array}$ \\
\hline 1 & $\begin{array}{l}\text { Visión } \\
\text { Artificial }\end{array}$ & $\begin{array}{l}\text { Captura y } \\
\text { visualización } \\
\text { de imagen }\end{array}$ & $100 \%$ & $100 \%$ & $100 \%$ \\
\hline 2 & $\begin{array}{l}\text { Visión } \\
\text { Artificial }\end{array}$ & $\begin{array}{c}\text { Extracción } \\
\text { de bordes y } \\
\text { contornos }\end{array}$ & $90 \%$ & $100 \%$ & $95 \%$ \\
\hline 3 & $\begin{array}{l}\text { Visión } \\
\text { Artificial }\end{array}$ & $\begin{array}{l}\text { Segmenta- } \\
\text { ción }\end{array}$ & $100 \%$ & $100 \%$ & $95 \%$ \\
\hline 4 & $\begin{array}{l}\text { Visión } \\
\text { Artificial }\end{array}$ & $\begin{array}{c}\text { Detección } \\
\text { y reconoci- } \\
\text { miento de } \\
\text { patrones }\end{array}$ & $95 \%$ & $100 \%$ & $90 \%$ \\
\hline 5 & $\begin{array}{l}\text { Comu- } \\
\text { nicación } \\
\text { inalám- } \\
\text { brica }\end{array}$ & $\begin{array}{c}\text { Sistema de } \\
\text { alerta auto- } \\
\text { mática }\end{array}$ & $100 \%$ & $100 \%$ & $100 \%$ \\
\hline
\end{tabular}

Fuente: autores

La evaluación es favorable, ya que el sistema SISREP cumple con los objetivos establecidos en el desarrollo de la propuesta y ha superado la prueba de módulo único y la prueba de grupo de módulos, con éxito. A su vez, la prueba de sistema completo obtuvo excelentes resultados en velocidad y exactitud; en la fiabilidad existe una reducción porcentual de entre $5 \%$ a $10 \%$, aproximadamente, debido al entorno operativo e iluminación del ambiente de trabajo del sistema. Complementariamente a las pruebas del sistema SISREP se realizó una verificación basada en los diagramas de flujo del sistema. La Tabla 6 muestra la verificación basada en la operatividad.

Tabla 6. Verificación basada en la operatividad.

\section{PRUEBAS DEL SISTEMA INTELIGENTE DE RECONOCIMIENTO DE PATRONES}

\begin{tabular}{cl} 
Nombre Prueba & Basada en el uso \\
\hline Realizada por & Programador \\
\hline Descripción & $\begin{array}{l}\text { Verificar el uso y el entorno de } \\
\text { trabajo del sistema SISREP }\end{array}$ \\
\hline
\end{tabular}

\begin{tabular}{cccc}
\hline $\mathbf{N}$ & $\begin{array}{c}\text { Catego- } \\
\text { ría }\end{array}$ & $\begin{array}{c}\text { Respuesta } \\
\text { esperada del } \\
\text { sistema PIVRA }\end{array}$ & Velocidad \\
\hline $\mathbf{1}$ & $\begin{array}{c}\text { Visión } \\
\text { Artificial }\end{array}$ & $\begin{array}{c}\text { Captura y visuali- } \\
\text { zación de imagen }\end{array}$ & $97 \%$ \\
\hline $\mathbf{2}$ & $\begin{array}{c}\text { Visión } \\
\text { Artificial }\end{array}$ & $\begin{array}{c}\text { Extracción de bor- } \\
\text { des y contornos }\end{array}$ & $95 \%$ \\
\hline $\mathbf{3}$ & $\begin{array}{c}\text { Visión } \\
\text { Artificial }\end{array}$ & Segmentación & \\
\hline & $\begin{array}{c}\text { Visión } \\
\text { Artificial }\end{array}$ & $\begin{array}{c}\text { Detección y re- } \\
\text { conocimiento de } \\
\text { patrones }\end{array}$ & $95 \%$ \\
\hline & $\begin{array}{c}\text { Comu- } \\
\text { nicación } \\
\text { inalám- } \\
\text { brica }\end{array}$ & $\begin{array}{c}\text { Sistema de alerta } \\
\text { automática }\end{array}$ & \\
\hline & & $100 \%$ \\
\hline
\end{tabular}

Fuente: autores

La verificación del sistema SISREP basada en la operatividad, estípula buenos resultados en virtud al entorno de trabajo; un valor porcentual promedio de $98,6 \%$ reflejan aquel valor cualitativo. Además, el valor porcentual beneficia la ergonomía y fiabilidad del sistema SISREP [8-11]. El diseño ha sido el óptimo puesto que la cámara permitió tener la visión correcta del producto haciendo que el sistema funcione adecuadamente, mediante la utilización de módulos Arduinos y la utilización de cable USB para la conexión del computador, evitando así una interrupción o un corte en la transferencia de datos durante el proceso.

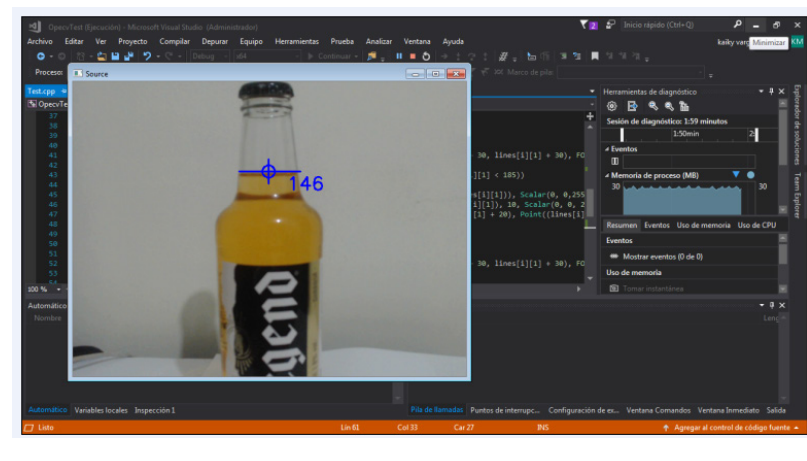

Figura 3. Adquisición de imágenes 
Observación: El algoritmo logra reconocer que la botella cuenta con un nivel de líquido superior al establecido. En la siguiente imagen, se presenta una botella con un nivel de líquido dentro de lo establecido, por lo tanto, el programa debería reconocerlo.
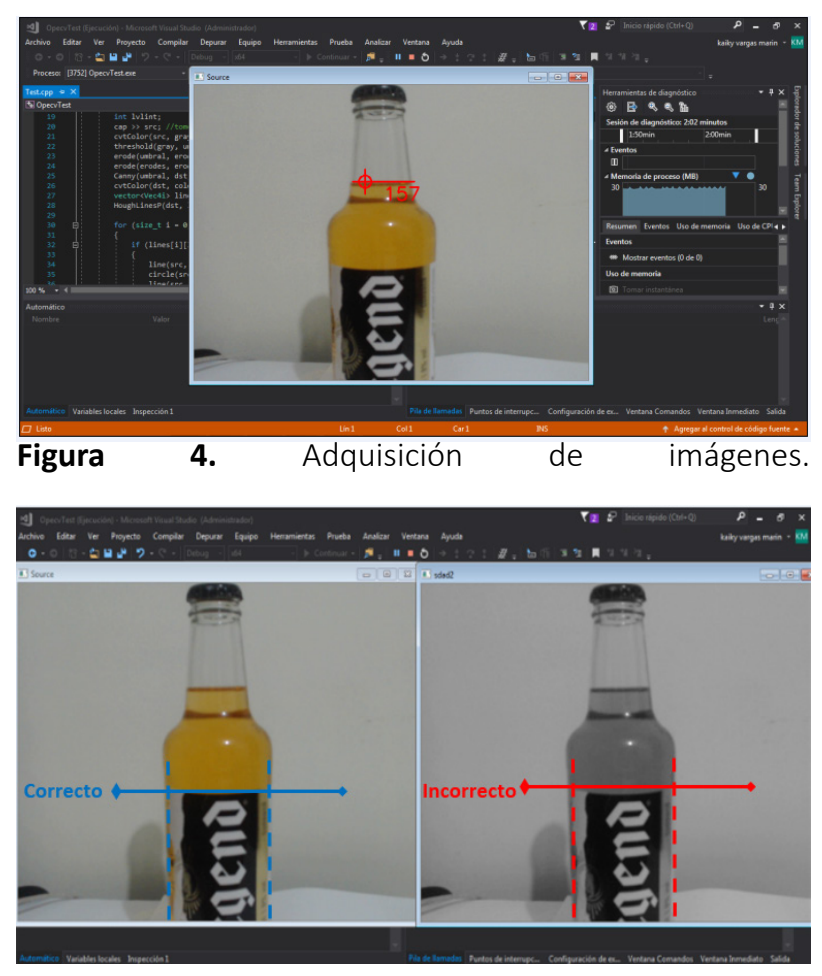

Figura 5. Adquisición de imágenes.

Observación: Se comprueba que el programa logra reconocer las diferentes fallas de la etiqueta tales como alineación y problemas de impresión o ralladuras y cortes

Tabla 7. Conteo de productos defectuosos mediante uso de visión artificial

\begin{tabular}{cccc}
\hline Muestras & Medición & $\begin{array}{c}\text { Nivel de } \\
\text { Referencia }\end{array}$ & $\begin{array}{c}\text { Comentario } \\
\text { del Sistema }\end{array}$ \\
\hline $1^{\circ}$ Lote & 1.00 & 3.00 & $\begin{array}{c}\text { Se cumplió } \\
\text { con la meta } \\
\text { esperada para } \\
\text { el periodo. }\end{array}$ \\
\hline $2^{\circ}$ Lote & 2.00 & 3.00 & $\begin{array}{c}\text { Se cumplió } \\
\text { con la meta } \\
\text { esperada para } \\
\text { el periodo. }\end{array}$ \\
\hline
\end{tabular}

\begin{tabular}{|c|c|c|c|}
\hline $3^{\circ}$ Lote & 4.00 & 3.00 & $\begin{array}{l}\text { Advertencia: } \\
\text { No se cum- } \\
\text { plió la meta } \\
\text { esperada para } \\
\text { el periodo. }\end{array}$ \\
\hline $4^{\circ}$ Lote & 3.00 & 3.00 & $\begin{array}{c}\text { Cumple la } \\
\text { meta, se } \\
\text { recomienda } \\
\text { hacer segui- } \\
\text { miento para no } \\
\text { sobrepasar el } \\
\text { límite. }\end{array}$ \\
\hline $5^{\circ}$ Lote & 0.10 & 3.00 & $\begin{array}{l}\text { Se cumplió } \\
\text { con la meta } \\
\text { esperada para } \\
\text { el periodo. }\end{array}$ \\
\hline $6^{\circ}$ Lote & 2.40 & 3.00 & $\begin{array}{l}\text { Se cumplió } \\
\text { con la meta } \\
\text { esperada para } \\
\text { el periodo. }\end{array}$ \\
\hline $7^{\circ}$ Lote & 6.00 & 3.00 & $\begin{array}{l}\text { Advertencia: } \\
\text { No se cum- } \\
\text { plió la meta } \\
\text { esperada para } \\
\text { el periodo. }\end{array}$ \\
\hline $8^{\circ}$ Lote & 2.00 & 3.00 & $\begin{array}{l}\text { Se cumplió } \\
\text { con la meta } \\
\text { esperada para } \\
\text { el periodo. }\end{array}$ \\
\hline $9^{\circ}$ Lote & 3.00 & 3.00 & $\begin{array}{c}\text { Cumple la } \\
\text { meta, se } \\
\text { recomienda } \\
\text { hacer segui- } \\
\text { miento para no } \\
\text { sobrepasar el } \\
\text { límite. }\end{array}$ \\
\hline $10^{\circ}$ Lote & 1.00 & 3.00 & $\begin{array}{l}\text { Se cumplió } \\
\text { con la meta } \\
\text { esperada para } \\
\text { el periodo. }\end{array}$ \\
\hline $11^{\circ}$ Lote & 5.00 & 3.00 & $\begin{array}{l}\text { Advertencia: } \\
\text { No se cum- } \\
\text { plió la meta } \\
\text { esperada para } \\
\text { el periodo }\end{array}$ \\
\hline $12^{\circ}$ Lote & 3.00 & 3.00 & $\begin{array}{c}\text { Cumple la } \\
\text { meta, se reco- } \\
\text { mienda hacer } \\
\text { seguimiento } \\
\text { para no sobre- } \\
\text { pasar el límite }\end{array}$ \\
\hline
\end{tabular}

Fuente: autores 
Ryan Abraham León León Bebeto Junior Beltran Jara Renato Cruz Saavedra Kendy Terrones Julcamoro Miguel Angel Aponte de la Cruz

Alexander Torres Verastegui

La tabla 7 nos muestra el conteo de productos defectuosos obtenidos al realizar el procesamiento de inspección con el sistema de visión artificial a una muestra de 12 lotes de los cuales por lote se escogió 10 unidades de botellas de ron de $275 \mathrm{ml}$. El resultado es comparado con un nivel de referencia de producto defectuoso que tiene la empresa definido como máximo, al realizar la inspección de los lotes se obtuvo que en el lote 3, 7, 11 se tiene un exceso de producto defectuoso de lo esperado en base a los parámetros de calidad establecidos.

$\begin{array}{lcccc}\text { Tabla } & \mathbf{8 .} & \text { Conteo } & \text { de } & \text { produc- } \\ \text { tos } & \text { defectuosos } & \text { usando } & \text { visión } & \text { Humané }\end{array}$

\begin{tabular}{|c|c|c|c|}
\hline Muestras & Medición & $\begin{array}{l}\text { Nivel de } \\
\text { Referencia }\end{array}$ & $\begin{array}{l}\text { Comentario } \\
\text { del Sistema }\end{array}$ \\
\hline $1^{\circ}$ Lote & 1.00 & 3.00 & $\begin{array}{l}\text { Se cumplió } \\
\text { con la meta } \\
\text { esperada para } \\
\text { el periodo. }\end{array}$ \\
\hline $2^{\circ}$ Lote & 2.00 & 3.00 & $\begin{array}{c}\text { Se cumplió } \\
\text { con la meta } \\
\text { esperada para } \\
\text { el periodo. }\end{array}$ \\
\hline $3^{\circ}$ Lote & 1.00 & 3.00 & $\begin{array}{l}\text { Se cumplió } \\
\text { con la meta } \\
\text { esperada para } \\
\text { el periodo. }\end{array}$ \\
\hline $4^{\circ}$ Lote & 3.00 & 3.00 & $\begin{array}{c}\text { Cumple la } \\
\text { meta, se } \\
\text { recomienda } \\
\text { hacer segui- } \\
\text { miento para no } \\
\text { sobrepasar el } \\
\text { límite. }\end{array}$ \\
\hline $5^{\circ}$ Lote & 0.10 & 3.00 & $\begin{array}{l}\text { Se cumplió } \\
\text { con la meta } \\
\text { esperada para } \\
\text { el periodo. }\end{array}$ \\
\hline $6^{\circ}$ Lote & 2.40 & 3.00 & $\begin{array}{l}\text { Se cumplió } \\
\text { con la meta } \\
\text { esperada para } \\
\text { el periodo. }\end{array}$ \\
\hline $7^{\circ}$ Lote & 3.00 & 3.00 & $\begin{array}{c}\text { Cumple la } \\
\text { meta, se reco- } \\
\text { mienda hacer } \\
\text { seguimiento } \\
\text { para no sobre- } \\
\text { pasar el límite }\end{array}$ \\
\hline
\end{tabular}

\begin{tabular}{|c|c|c|c|}
\hline $8^{\circ}$ Lote & 2.00 & 3.00 & $\begin{array}{c}\text { Se cumplió } \\
\text { con la meta } \\
\text { esperada } \\
\text { para el } \\
\text { periodo. }\end{array}$ \\
\hline $9^{\circ}$ Lote & 3.00 & 3.00 & $\begin{array}{c}\text { Cumple la } \\
\text { meta, se } \\
\text { recomienda } \\
\text { hacer segui- } \\
\text { miento para no } \\
\text { sobrepasar el } \\
\text { límite. }\end{array}$ \\
\hline $10^{\circ}$ Lote & 1.00 & 3.00 & $\begin{array}{c}\text { Se cumplió } \\
\text { con la meta } \\
\text { esperada } \\
\text { para el } \\
\text { periodo. }\end{array}$ \\
\hline $11^{\circ}$ Lote & 3.00 & 3.00 & $\begin{array}{l}\text { Cumple la } \\
\text { meta, se } \\
\text { recomienda } \\
\text { hacer segui- } \\
\text { miento para no } \\
\text { sobrepasar el } \\
\text { límite. }\end{array}$ \\
\hline $12^{\circ}$ Lote & 2.00 & 3.00 & $\begin{array}{c}\text { Se cumplió } \\
\text { con la meta } \\
\text { esperada } \\
\text { para el } \\
\text { periodo }\end{array}$ \\
\hline
\end{tabular}

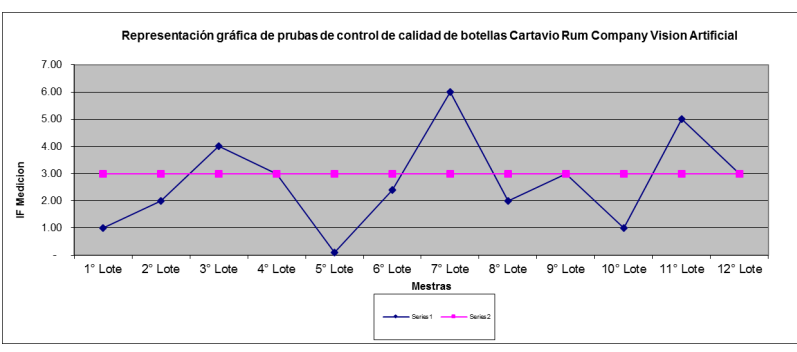

Figura 6. Conteo de Productos defectuosos uso de Visión Artificial.

El gráfico muestra que los datos obtenidos al emplear la visión artificial en la línea de producción de la empresa Cartavio Rum Company existe un alto índi-ce de productos defectuosos en los lotes $3,7,11$ puesto que se encuentran fuera de los parámetros de calidad establecidos por la empresa. 


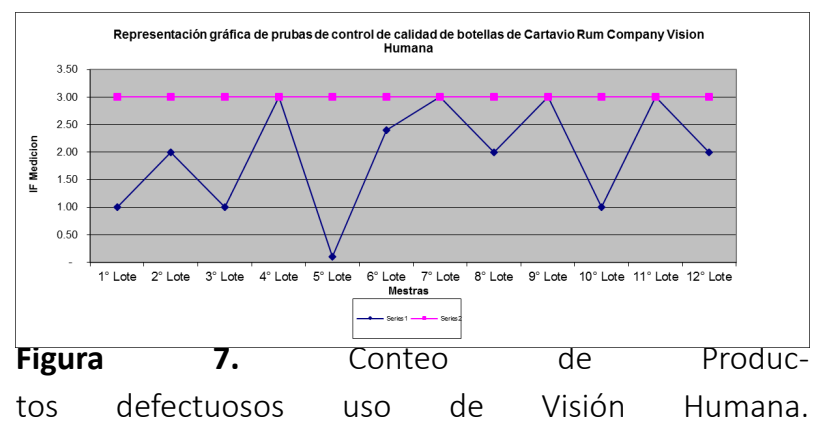

El gráfico evidencia que los datos obtenidos al realizar la inspección de los productos defectuosos de manera visual con el ojo humano no existen un alto índice de productos defectuosos, al contrario las observaciones realizadas a los 12 lotes arrojan que se encuentran dentro de los parámetros de calidad establecidos por la empresa.

Realizando la inspección de manera detenida por los encargados del área de control de calidad de la empre-sa, se comprueba que los datos arrojados por el sistema de visión artificial muestran una eficiencia del 95\% mientras que la inspección visual realizada por el ojo humano muestra una eficiencia del 55\%. Por lo que se corrobora que la visión artificial es la mejor opción para mantener un estricto control de calidad de la línea de producción de la empresa Cartavio Rum Company.

\section{CONCLUSIONES}

El objetivo principal de este proyecto fue el diseño de un sistema de visión artificial, el cual fue alcanzado con éxito. El Sistema desarrollado permitió identificar el nivel de llenado en botellas de ron de la empresa Carta-vio Rum Company de $250 \mathrm{ml}$ y su respectiva clasificación de acuerdo a los parámetros de control de calidad establecidos.

El sistema diseñado brinda una perspectiva más clara de los alcances que tiene la tecnología basada en visión artificial. A diferencia de los métodos tradicionales, este sistema permite inspeccionar el 100\% de la produc-ción, eliminado cualquier posibilidad de error que pueda afectar la satisfacción del cliente.
La aplicación posee contadores automáticos que almacenan datos sobre el estado actual de la inspección. Esta información puede ser útil en la elaboración de reportes o análisis de productividad.

El sistema de inspección fue desarrollado contemplando las necesidades reales de la industria, logrando determinar los parámetros de control de calidad más adecuados para favorecer la productividad.

Debido a que no existe una forma concreta de encarar un problema con visión artificial, se ha desarrollado una propuesta realizando varias pruebas, en ellas se logró determinar las herramientas y técnicas que más se ajustan a este problema.

El prototipo presenta un leve margen de error en la medición, atribuido principalmente a las características técnicas de la cámara utilizada, debido a que está no ha sido diseñada con este propósito dándonos un $98.6 \%$ de eficiencia operacional.

\section{REFERENCIAS}

[1] I. Herrero, "Ingeniería en Automatización y Control Industrial,". Ed. Quilmes: Universidad Nacional de Quilmes, 2005. pp. 19.

[2] A. Hornberg, "Handbook Of Machine Vision,". Ed. Weinheim: WILEY-VCH Verlag $\mathrm{GmbH} \&$ Co $\mathrm{KGaA}$, 2006. 798 p.

[3] R. Gonzalez, and C. Woods, "Digital Image Processing,". Second edition. Upper Saddle River, New Jersey 07458: Prentice Hall, 2002. 793 p.

[4] T. Klinger. "Image Processing With Labview And Imaq Vision,". Upper Saddle River, New Jersey 07458: Prenti-ce Hall, 2003. 319 p.

[5] I. Minchala, "Procesamiento Digital de Imágenes,". Ambato: agosto de 2008. (Presentado en: Curso de proce-samiento digital de imágenes basadas en computador: del 19 al 23 de agosto de 2008).

[6] J. Russ. "The Image Processing Handbook". Thrird edition. 2000 N.W. Corporate Blvd., Boca 
Raton, Florida: CRC Press LLC, 1999. 984 p.

[7] T. Benavides, "OpenCV y el diseño de filtros digitales,". Revista Digital de Investigación y Educación. Disponible en http://www.ingenieria. unam.mx/ sagfi/icode/OpenCV-filtros.pdf[

[8] J. P. Cáceres, "Sistema de Visión Artificial Para Inspección del Nivel de Llenado de Bebidas Embotelladas,". Universidad Técnica de Ambato, Ambato - Ecuador, 2011.

[9] G. E. Murillo Quishpe y S. D. Montaluisa Pilatasig, "Control e Inspección de Llenado de Botellas Aplicando Herramientas de Visión Artificial para el Laboratorio de Neumática e Hidrónica de la ESPE Sede Latacunga,". Escuela Politécnica del Ejército, Latacunga - Ecuador, 2010.

[10] V. Vargas Baeza, "Sistema de Visión Artifical para el Control de Calidad en Piezas Cromadas,". Instituto Politécnico Nacional, México D.F. - México, 2010.

[11] J. Porras y M. De la Cruz, "Clasification System Based On Computer Vision,". Universidad Ricardo Palma, Lima - Perú 